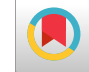

\title{
Preparation, Characterization, and Application of Silica Aerogel for Adsorption of Phenol: An In-Depth Isotherm Study
}

\author{
Alireza Rahmani ${ }^{1}$, Fatemeh Nazemi ${ }^{2}$, Fateme Barjasteh-Askari ${ }^{3,4,{ }^{*}}$ and Mojtaba Davoudi ${ }^{3,4}$ \\ ${ }^{1}$ Department of Environmental Health Engineering, Faculty of Health and Research Center for Health Sciences, Hamadan University of Medical Sciences, Hamadan, Iran \\ ${ }^{2}$ Food and Drug Industrial Administration, Hamadan University of Medical Sciences, Hamadan, Iran \\ ${ }^{3}$ Department of Environmental Health Engineering, School of Health, Torbat Heydariyeh University of Medical Sciences, Torbat Heydariyeh, Iran \\ ${ }^{4}$ Health Sciences Research Center, Torbat Heydariyeh University of Medical Sciences, Torbat Heydariyeh, Iran \\ "Corresponding author: Department of Environmental Health Engineering, School of Health, Torbat Heydariyeh University of Medical Sciences, Razi St., North Ferdowsi Blvd., \\ Torbat Heydariyeh, Iran. Tel: +98-5152224038, Email: fatemeh.barjasteh@gmail.com
}

\section{Received 2016 October 06; Revised 2017 June 12; Accepted 2017 August 01.}

\begin{abstract}
This study evaluated silica aerogel as an adsorbent for phenol removal from aqueous solutions. Silica aerogel was prepared through the sol-gel process and characterized by different analyses. Then, it was used for phenol removal under various conditions of operational parameters. Also, twelve isotherm parameters were employed to describe the behavior of phenol-silica aerogel adsorption system. The chemical structural analysis confirmed -OH functional groups in amorphous $\mathrm{SiO}_{2}$ and proved the adsorption of phenol onto the surface of silica aerogel. The findings of the adsorptive behavior of silica aerogel toward phenol showed increasing $\mathrm{pH}$, up to 8.5, and contact time, and adsorbent dose increased the phenol removal. The removal efficiency reached over $90 \%$ when phenol concentration was below $50 \mathrm{mg} \mathrm{L}^{-1}$. The reaction kinetics followed the pseudo-first order model. The isotherm study showed that equilibrium adsorption data were well-described by Freundlich and Halsey equations, among two-parameter isotherms, and Hill, Sips, and Koble-Corrigan, among three-parameter isotherms. Jovanovic and BET were the worst isotherm models for prediction of experimental equilibrium data. The maximum adsorption capacity of $75.23 \mathrm{mg} . \mathrm{g}^{-1}$ was calculated in phenol-silica aerogel adsorption system. The study showed silica aerogel as an efficient adsorbent to remove phenol from phenol-containing solutions.
\end{abstract}

Keywords: Adsorption, Kinetics, Phenol, Silica Aerogel, Aqueous Solution

\section{Background}

Due to human activities, especially in the industrial section, various chemical compounds may find their way in the environment, including water, soil, and air. Phenol is one of these highly toxic chemical compounds, which can be found in industrial wastewater, such as chemical, pharmaceutical, and petrochemical effluents $(1,2)$. This aromatic compound is commonly used in chemical industries in production of resins, plastics, fibers, and detergents (3). High concentrations of phenol can be lethal through inhalation, contact, ingestion, etc.

In the recent years, due to concerns arising from environmental pollution and water shortage, wastewater treatment and reuse is considered as an important issue. Wastewater treatment operations are carried out through physical, chemical, and/or biological processes to meet the current standards for discharge of effluent to the environment. There are various methods for phenol removal from aqueous solutions, such as Fenton-based technologies (3), ozonation (4), coagulation (5), biological processes (6), adsorption (7), electro-oxidation (8), and electrocoagulation (9).
One of the most commonly used techniques for phenol removal is adsorption. Cost-effectiveness, ease of operation, and lack of sensitivity to toxic substances are some advantages, which make this technique more efficient (10). Adsorption is a process, in which pollutant molecules are transferred from the liquid phase to a solid surface. Activated carbon is a traditional adsorbent, which has been widely used for removal of various pollutants (10). This material, however, has been accompanied by drawbacks, such as limited selectivity and low modification flexibility (11). As a result, a trend has been raised towards new adsorbents with fewer limitations. Aerogel is called "frozen smoke" due to its lightness. Aerogels were first synthesized in the 1930's. Silica aerogel is one of the most common forms of aerogels, which contains small pores, such as micropores and mesopores, which result in a large specific surface area responsible for adsorption. Thus, Silica aerogel is a suitable candidate to substitute the traditional adsorbents, thanks to its high specific area (500 to $1000 \mathrm{~m}^{2} / \mathrm{g}$ ), high porosity (up to 99\%), and high modification capability (12-14). Up to now, this adsorbent has been widely applied to remove various toxic compounds, such as heavy metals (14), 
Benzene, Toluene, Ethylbenzene, and Xylenes (BTEX) compounds (15), dyes (11), and so on. As far as the authors are aware, however, there is a limited knowledge about the adsorptive behavior of silica aerogel for phenol removal under various conditions of operation. In a study conducted by Qin et al. (12), for example, silica aerogel with different extents of hydrophobicity was prepared and utilized to remove phenol while they focused only on kinetic/isotherm studies and ignored the effect of operational parameters on phenol adsorption.

\section{Objectives}

The aim of the present study, thereby, was to synthesize, characterize, and utilize silica aerogel for phenol adsorption by determining the effect of the most important operational parameters, including contact time, solution $\mathrm{pH}$, phenol concentration, and adsorbent dose. The kinetics and isotherms of adsorption were also investigated.

\section{Methods}

All the chemicals used in this study were purchased from Merck. Phenol $\left(\mathrm{C}_{6} \mathrm{H}_{5} \mathrm{OH}, 99 \%\right.$ purity) was used to prepare test solutions. $\mathrm{NaOH}$ or $\mathrm{H}_{2} \mathrm{SO}_{4}$ solutions $(1 \mathrm{~N})$ were applied to adjust $\mathrm{pH}$ during the experiments using a $\mathrm{pH}$ meter (Sartorius, model PP-50). Sodium silicate $\left(\mathrm{Na}_{2} \mathrm{SiO}_{3}\right.$, 99.5\% purity) was used for preparation of sol-gel. Distilled water was prepared by a water distiller (Fater Electronic Water Distiller, model 2104, Iran).

\subsection{Adsorbent Preparation}

Silica aerogel preparation was carried out by the sol-gel process (13,16-18). At first, the original sol was produced by preparing a saturated solution of $\mathrm{Na}_{2} \mathrm{SiO}_{3}$. Insoluble sediments and residues were separated from the solution by filtration. Then, $50 \mathrm{~mL}$ of $12 \mathrm{~N} \mathrm{HCl}$ was added to the saturated solution gradually, during one hour. The solution remained stable for 24 hours under acidic conditions. During this period, sodium silicate turned to sol-gel through polymerization. The obtained gel was slowly separated from the solvent by filtration. The separated gel was placed in ethanol for two hours at $50{ }^{\circ} \mathrm{C}$. This treatment was repeated several times with fresh ethanol to ensure the replacement of accumulated water in gel sites. To prevent drying and folding after cooling, the wet gel was placed under high pressure and temperature $\left(245^{\circ} \mathrm{C}\right.$ and $\left.12.50 \mathrm{MPa}\right)$ to reach the supercritical temperature point of the solvent. Finally, the pressure was dropped to evacuate the solvents completely from the gel sites.

\subsection{Adsorbent Characterization}

Morphological and structural patterns of the adsorbent were examined using Scanning Electron Microscope (SEM, Philips model XL-C) and X-Ray Diffraction (XRD, Philips model X PER MPD) analyzer, respectively. Surface functional groups of silica aerogel were determined through Fourier Transform Infrared (FT-IR) spectroscopy (Perkin Elmer Spectrum 1600) in the range of 400 to 4000 $\mathrm{cm}^{-1}$. Nuclear Magnetic Resonance (NMR) spectroscopy analyzer (Avance $200 \mathrm{MHZ}$ ) was used to determine the molecular structure of the prepared aerogel. The zero-point charge $\mathrm{pH}$ (pHzpc) of adsorbent was determined according to Dastgheib et al. (19). Briefly, $0.5 \mathrm{~g}$ of silica aerogel was added to $30 \mathrm{~mL}$ of $0.1 \mathrm{M} \mathrm{NaCl}$ solutions. The $\mathrm{pH}$ of saline solutions were previously adjusted between two and twelve. After 48 hours of agitation at $120 \mathrm{rpm}$, the values of final $\mathrm{pH}$ of filtered solutions were measured and plotted against initial $\mathrm{pH}$ values to determine the $\mathrm{pHzpc}$.

\subsection{Adsorption Experiments}

For all the batch experiments, glassware and bottles were washed and rinsed with $\mathrm{HNO}_{3}$ and then by distilled water before usage. Adsorption experiments were performed in a batch reactor to determine the effect of contact time (5 to 180 minutes), solution $\mathrm{pH}$ (3 to 12), initial phenol concentration (20 to $500 \mathrm{mg} \mathrm{L}^{-1}$ ), and adsorbent dose ( 0.4 to $8.0 \mathrm{~g} \mathrm{~L}^{-1}$ ) on the adsorption process. The volume of sample solutions was $250 \mathrm{~mL}$ and the speed of stirring was kept at $200 \mathrm{rpm}$. All the experiments were performed at room temperature $\left(20 \pm 1^{\circ} \mathrm{C}\right)$, according to one factor at a time design. At the end of each experiment, the solid phase was separated from the solution by centrifugation (Sigma ${ }^{\circledR}-301$ centrifuge apparatus) at $5000 \mathrm{rpm}$ for five minutes. The kinetic study was conducted by using data obtained in contact time experiments within 180 minutes at initial phenol concentration of 50 and $100 \mathrm{mg} \mathrm{L}^{-1}$. The pseudo-first order and pseudo-second order kinetic models were employed to evaluate the experimental data.

\subsection{Adsorption Isotherms}

The isotherm study was carried out using the equilibrium data that were obtained by varying phenol concentrations ( 20 to $500 \mathrm{mg} \mathrm{L}^{-1}$ ). In this study, twelve isotherm models were employed to investigate the equilibrium adsorption of phenol onto silica aerogel. These isotherm models are summarized in Table 1 . In all the equations, $\mathrm{q}_{\mathrm{e}}\left(\mathrm{mg} \mathrm{g}^{-1}\right)$ denotes the loaded amount of adsorbate onto the adsorbent at equilibrium and $\mathrm{C}_{\mathrm{e}}\left(\mathrm{mg} \mathrm{L}^{-1}\right)$ represents the equilibrium concentration of adsorbate in the solution. In every equation, both $\mathrm{q}_{\mathrm{e}}$ and $\mathrm{C}_{\mathrm{e}}$ are known from the experiments 
while the other parameters are revealed from the experimental data fitting the relevant equation. The fitting of data to the non-linear expression of isotherm models was carried out using the OrigingPro9 software ${ }^{\circledR}$. In order to discover the best model, four error functions were utilized, including adjusted coefficient of determination (Adj. $\mathrm{R}^{2}$ ), sum of squared errors (SSE), nonlinear chi-square $\left(\chi^{2}\right)$, and Akaike Information Criterion (AIC). The Adj. $\mathrm{R}^{2}$ values close to one along with SSE and $\chi^{2}$ values close to zero indicate a better description of experimental data by the model. The AIC is used for final judgment between the models. A model with lower AIC value, compared to the value of other models, is a more adequate model for experimental data description (20).

\subsection{Measurement and Calculations}

Unknown concentrations of phenol were determined according to the method 5530D of standard methods for the examination of water and wastewater (24). Briefly, in this colorimetric method, 4-aminoantipyrine was added to the phenol-containing solution and the intensity of color resulting from the reaction was determined at maximum wavelength of $\lambda=510 \mathrm{~nm}$, using a Hatch-DR 5000 UVVis spectrophotometer. The measured intensity was converted to phenol concentration using a calibration curve.

The phenol removal efficiency $(R, \%)$ and amount of phenol adsorbed on silica aerogel $\left(\mathrm{q}_{\mathrm{e}}, \mathrm{mg} \mathrm{g}^{-1}\right)$ were calculated using the below equations:

$R=\frac{C_{0}-C_{e}}{C_{0}} \times 100$

$q_{e}=\frac{C_{0}-C_{e}}{m} \times V$

where $\mathrm{C}_{0}$ and $\mathrm{C}_{\mathrm{e}}$ are the initial and final concentrations of phenol $\left(\mathrm{mg} \mathrm{L}^{-1}\right)$, respectively, $\mathrm{m}$ is the adsorbent mass $(\mathrm{g})$, and $\mathrm{V}$ is the solution volume (L).

\section{Results}

\subsection{Silica Aerogel Characteristics}

The SEM image in Figure 1, which was obtained at two different magnifications, shows morphological characteristics of silica aerogel. The XRD pattern of silica aerogel in Figure 2 shows a broad peak close to $20^{\circ}(2 \theta)$.

Figure 3 depicts the FTIR spectra of silica aerogel before and after phenol adsorption. As shown in Figure $3 \mathrm{~A}$, there is a peak at $3400.72 \mathrm{~cm}^{-1}$ related to the hydroxyl functional group (-OH) before phenol adsorption (25). The peak that appeared around 1600 to $1700 \mathrm{~cm}^{-1}$ is related to stretching vibration of $\mathrm{OH}$ groups as a result of physical absorption of water on the particles (26). The absorption peak at 1158 $\mathrm{cm}^{-1}$ is attributed to O-Si-O vibration. The FTIR spectrum after phenol adsorption (Figure $3 \mathrm{~B}$ ) shows a peak shifted to $3342 \mathrm{~cm}^{-1}$ and a new one appeared at $3213 \mathrm{~cm}^{-1}$. The peak at $1155.96 \mathrm{~cm}^{-1}$, assigned to O-Si-O, appeared more intense than the corresponding peak in the spectrum before adsorption. The peaks around $1075 \mathrm{~cm}^{-1}$ and $751 \mathrm{~cm}^{-1}$ may be attributed to aromatic C-H. Also, the peak at $799 \mathrm{~cm}^{-1}$ could be assigned to phenolic $\mathrm{C}-\mathrm{OH}$ stretching (27). The peak around wave number of $619 \mathrm{~cm}^{-1}$ is due to the phenol ring (28). The shifted and new peaks appeared in this spectrum support the idea of phenol adsorption in the network of aerogel.

The NMR spectra of synthesized aerogel before and after phenol adsorption are given in Figure 4. In the spectrum before and after the adsorption, a chemical shift around $2.2 \delta$ was observed. In the spectrum after adsorption, however, a weak chemical shift was observed at $4.7 \delta$ and another shift in the region of $7.2 \delta$.

The pHzpc of silica aerogel was determined to characterize surface chemistry of the adsorbent. The obtained results showed that the pHzpc was equal to 6.9.

\subsection{Effect of Operational Parameters}

\subsubsection{Effect of Contact Time on Phenol Removal}

In order to determine the effect of contact time on phenol adsorption onto silica aerogel, a series of contact time experiments were conducted at two different initial concentrations of phenol (50 and $100 \mathrm{mg} \mathrm{L}^{-1}$ ). Based on the obtained results, the maximum removal efficiency was obtained as $95.8 \%$ and $81.2 \%$ for 50 and $100 \mathrm{mgL}^{-1}$, respectively (Figure $5 \mathrm{~A}$ ). Also, it was observed that the time required to reach equilibrium was 45 minutes for concentration of 50 $\mathrm{mgL}^{-1}$ and 60 minutes for $100 \mathrm{mgL}^{-1}$, which means the equilibrium time was a function of solute concentration.

\subsubsection{Effect of $\mathrm{pH}$ on Phenol Removal}

In the present study, the effect of solution $\mathrm{pH}$ on phenol adsorption was examined in the $\mathrm{pH}$ range of 3 to 12 . According to Figure $5 \mathrm{~B}$, phenol removal efficiency increased by rising $\mathrm{pH}$ and reached its maximum at $\mathrm{pH}$ 8.5. Then, it slightly decreased at $\mathrm{pH} 10$ and reached its minimum at $\mathrm{pH}$ 12.

\subsubsection{Effect of Initial Concentration of Phenol on the Adsorption Process}

The obtained results on the effect of initial concentration of phenol are shown in Figure 5 C. As indicated, with an increase in initial phenol concentration, the removal efficiency decreased and on the contrary, the equilibrium adsorption capacity increased. For instance, at initial concentration of $20 \mathrm{mg} \mathrm{L}^{-1}$, the removal efficiency reached more 


\begin{tabular}{|c|c|c|c|}
\hline Model & Non-linear expression & Parameters & References \\
\hline Langmuir & $q_{e}=\frac{b q_{m} C_{e}}{1+b C_{e}}$ & $\begin{array}{l}\mathrm{b}=\text { Langmuir isotherm constant }\left(\mathrm{L} \mathrm{mg}^{-1}\right), \mathrm{q}_{\mathrm{m}}=\text { maximum monolayer coverage } \\
\text { capacities }\left(\mathrm{mg} \mathrm{g}^{-1}\right)\end{array}$ & (21) \\
\hline Freundlich & $q_{e}=K_{f} C_{e}^{1 / n}$ & $\begin{array}{l}\mathrm{K}_{\mathrm{f}}=\text { Freundlich isotherm constant }\left(\mathrm{mg} \mathrm{g}^{-1}\right)\left(\mathrm{Lg}^{-1}\right)^{1 / \mathrm{n}} \text {, related to adsorption } \\
\text { capacity, } \mathrm{n}=\text { Freundlich isotherm constant related to adsorption intensity }\end{array}$ & (21) \\
\hline Jovanovic & $q_{e}=q_{m}\left(1-e^{K_{j} C_{e}}\right)$ & $\begin{array}{l}\mathrm{q}_{\mathrm{m}}=\text { maximum adsorption capacity }\left(\mathrm{mg} \mathrm{g}^{-1}\right), \mathrm{K}_{\mathrm{j}}=\text { Jovanovic isotherm constant } \\
\left(\mathrm{L} \mathrm{mg}^{-1}\right)\end{array}$ & (22) \\
\hline Halsey & $q_{e}=\left(\frac{K_{H}}{C_{e}}\right)^{1 / n_{H}}$ & $\mathrm{~K}_{\mathrm{H}}=$ Halsey isotherm constant, $\mathrm{n}_{\mathrm{H}}=$ Halsey isotherm constant & (23) \\
\hline Hill & $q_{e}=\frac{q_{S H} C_{e}^{n} H}{K_{D}+C_{e}^{n} H}$ & $\begin{array}{l}\mathrm{q}_{\mathrm{SH}}=\text { Hill isotherm maximum uptake saturation }\left(\mathrm{mg} \mathrm{L}^{-1}\right), \mathrm{n}_{\mathrm{H}}=\text { Hill } \\
\text { cooperativity coefficient of the binding interaction, } \mathrm{K}_{\mathrm{D}}=\text { Hill constant }\end{array}$ & (21) \\
\hline Sips & $q_{e}=\frac{K_{S} C_{e}^{B} S}{1+A_{S} C_{e}^{B} S}$ & $\begin{array}{l}\mathrm{K}_{\mathrm{S}}=\text { Sips isotherm model constant }\left(\mathrm{L} \mathrm{g}^{-1}\right), B_{S}=\text { Sips isotherm model exponent, } \\
A_{S}=\text { Sips isotherm model constant }\left(\mathrm{L} \mathrm{mg}^{-1}\right)\end{array}$ & (21) \\
\hline Koble-Corrigan & $q_{e}=\frac{a C_{e}^{n}}{1+b C_{e}^{n}}$ & $\begin{array}{l}\mathrm{a}=\text { Koble-Corrigan isotherm constant }\left(\mathrm{L}^{\mathrm{n}} \mathrm{mg}^{1-\mathrm{n}} \mathrm{g}^{-1}\right), \mathrm{n}=\text { adsorption intensity, } \mathrm{b}= \\
\text { Koble-Corrigan isotherm constant }\left(\mathrm{Lgg}^{-1}\right)^{\mathrm{n}}\end{array}$ & (21) \\
\hline Toth & $q_{e}=\frac{K_{T} C_{e}}{\left(A_{T}+C_{e}\right)^{1} / T}$ & $\begin{array}{l}\mathrm{K}_{\mathrm{T}}=\text { Toth isotherm constant }\left(\mathrm{mg} \mathrm{g}^{-1}\right), \mathrm{A}_{\mathrm{T}}=\text { Toth isotherm constant }\left(\mathrm{L} \mathrm{mg}^{-1}\right), \mathrm{T}= \\
\text { Toth isotherm constant }\end{array}$ & (21) \\
\hline Redlich-Peterson & $q_{e}=\frac{k_{R P} C_{e}}{1+a_{R P} C_{e}^{b} R P}$ & $\begin{array}{l}\mathrm{k}_{\mathrm{RP}}=\text { Redlich-Peterson isotherm constant }\left(\mathrm{L} \mathrm{g}^{-1}\right), \mathrm{a}_{\mathrm{RP}}=\text { Redlich-Peterson } \\
\text { isotherm constant }\left(\mathrm{mg} \mathrm{L}^{-1}\right)^{-\mathrm{bRP}}, \mathrm{b}_{\mathrm{RP}}=\text { Redlich-Peterson isotherm exponent }\end{array}$ & (21) \\
\hline Radke-Prausnitz & $q_{e}=\frac{a_{R P} r_{R} C_{e}^{B} R}{\left(a_{R P}+r_{R}+C_{e}^{\left(B_{R}-1\right)}\right)}$ & $\begin{array}{l}\mathrm{a}_{\mathrm{RP}}=\text { Radke-Prausnitz isotherm model constant, } \mathrm{r}_{\mathrm{R}}=\text { Radke-Prausnitz isotherm } \\
\text { model constant, } \mathrm{B}_{\mathrm{R}}=\text { Radke-Prausnitz isotherm model exponent }\end{array}$ & (21) \\
\hline Khan & $q_{e}=\frac{q_{s} b_{k} C_{e}}{\left(1+b_{K} C_{e}\right)^{a} K}$ & $\begin{array}{l}\mathrm{qs}_{\mathrm{s}}=\text { theoretical isotherm saturation capacity }\left(\mathrm{mg} \mathrm{g}^{-1}\right), \mathrm{b}_{\mathrm{K}}=\text { Khan isotherm } \\
\text { model constant, } \mathrm{a}_{\mathrm{K}}=\text { Khan isotherm model exponent }\end{array}$ & (21) \\
\hline BET & $q_{e}=\frac{q_{s} C_{B E T} C_{e}}{\left(\left(C_{s}-C_{e}\right)\left[1+\left(C_{B E T}-1\right)\left(\frac{C_{e}}{C_{s}}\right)\right]\right)}$ & $\begin{array}{l}\mathrm{q}_{\mathrm{S}}=\text { theoretical isotherm saturation capacity }\left(\mathrm{mg} \mathrm{g}^{-1}\right), \mathrm{C}_{\mathrm{BEE}}=\mathrm{BET} \text { adsorption } \\
\text { isotherm related to the energy of surface interaction }\left(\mathrm{L} \mathrm{mg}^{-1}\right), \mathrm{C}_{\mathrm{S}}=\text { adsorbate } \\
\text { monolayer saturation concentration }\left(\mathrm{mg} \mathrm{L}^{-1}\right)\end{array}$ & $(21)$ \\
\hline
\end{tabular}
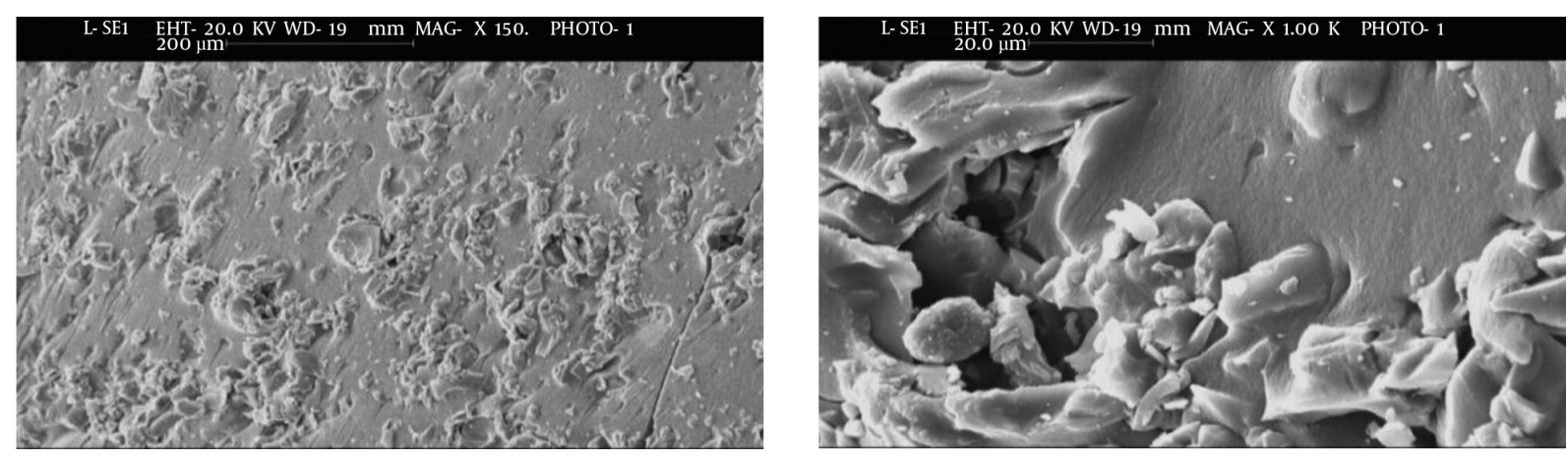

Figure 1. SEM image of prepared silica aerogel at 150x and 1000x magnifications

than $99 \%$ with adsorption capacity of $9.95 \mathrm{mg} \mathrm{g}^{-1}$, whereas at initial phenol of $500 \mathrm{mgL}^{-1}$, these values were $31.5 \%$ and $78.75 \mathrm{mg} \mathrm{g}^{-1}$, respectively.

\subsubsection{Effect of Silica Aerogel Dosage on Phenol Removal}

Figure $5 \mathrm{D}$ shows the effect of various applied doses of silica aerogel on the removal efficiency and amount of loaded phenol. As indicated, the adsorption efficiency increased with an increase in adsorbent dose; with increas- ing silica aerogel from 0.4 to $8.0 \mathrm{~g} \mathrm{~L}^{-1}$, the removal efficiency increased from 23.3 to $98.8 \%$. On the contrary, the loaded amount of phenol onto silica aerogel decreased from 58.3 to $12.5 \mathrm{mg} \mathrm{g}^{-1}$ by increasing adsorbent dose from 0.4 to 8.0 $\mathrm{g} \mathrm{L}^{-1}$.

\subsection{Adsorption Kinetics}

The kinetics of adsorption was determined to understand the nature of the adsorption process. In this study, 


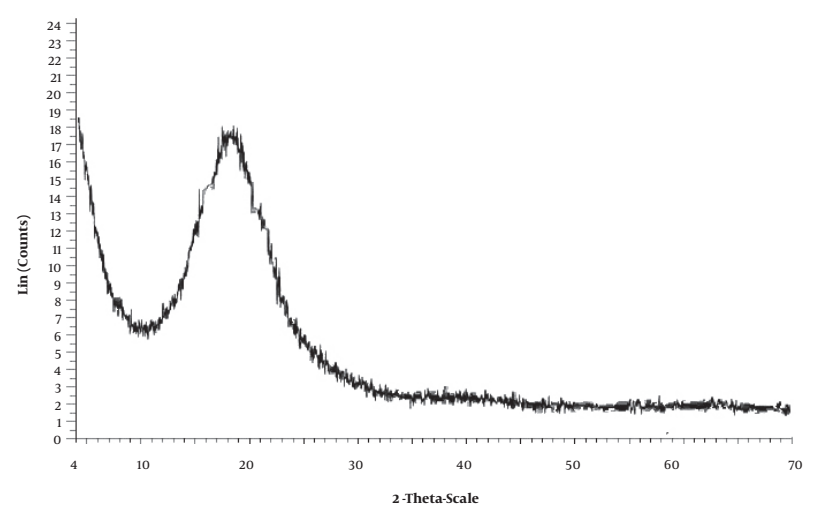

Figure 2. XRD pattern of silica aerogel

the experimental data were analyzed using the non-linear forms of pseudo-first order and pseudo second order kinetic models. The pseudo-first order kinetic model is:

$q_{t}=q_{e}\left(1-e^{-k_{1} t}\right)$

where $\mathrm{q}_{\mathrm{t}}$ and $\mathrm{q}_{\mathrm{e}}$ are the amount of solute loaded on adsorbent $\left(\mathrm{mg} \mathrm{g}^{-1}\right)$ at time $\mathrm{t}(\mathrm{min})$ and equilibrium, respectively, and $\mathrm{k}_{1}$ is the constant for pseudo-first order kinetic model $\left(\mathrm{min}^{-1}\right)$. The pseudo-second order kinetic model is:

$q_{t}=q_{e} \frac{q_{e} k_{2} t}{1+q_{e} k_{2} t}$

where $k_{2}$ is the constant for pseudo-second order kinetic equation $\left(\mathrm{g} \mathrm{mg}^{-1} \mathrm{~min}^{-1}\right)$, and other parameters have been previously defined. The plots of data fitting the kinetic models are presented in Figure 6. As indicated, the higher amounts of phenol loaded onto silica aerogel were obtained at a concentration of $100 \mathrm{mg} \mathrm{L}^{-1}$ compared to 50 $\mathrm{mg} \mathrm{L}^{-1}$. Table 2 lists the kinetic parameters and indicators of quality of fit. As observed, the pseudo-first order kinetic equation better described the experimental data for both investigated phenol concentrations, due to the higher values of Adj. $\mathrm{R}^{2}$ and lower values of $\chi^{2}$ and SSE. Also, the pseudo-first order kinetic equation could predict the experimental $\mathrm{q}_{\mathrm{e}}$ more accurately than the pseudo-second order kinetic equation.

Intra-particle diffusion was also investigated by using the Weber-Morris model, as follows:

$q_{t}=k_{i d} t / 2+C$

In this equation, $\mathrm{q}_{\mathrm{t}}\left(\mathrm{mg} \mathrm{g}^{-1}\right)$ is the amount of dye adsorbed at time $\mathrm{t}(\mathrm{min}), \mathrm{k}_{\mathrm{id}}$ denotes the intra-particle diffusion rate constant $\left(\mathrm{mg}\left(\mathrm{g} \mathrm{min}^{1 / 2}\right)^{-1}\right)$, and $\mathrm{C}$ represents a constant $\left(\mathrm{mg} \mathrm{g}^{-1}\right)$. Figure 7 demonstrates the plot of $\mathrm{q}_{\mathrm{t}}$ versus $\mathrm{t}^{1 / 2}$ to quantify $\mathrm{k}_{\mathrm{id}}$ as the slope of the line and $\mathrm{C}$ as the intercept. As indicated, the experimental data give two distinct lines with different slopes.

\subsection{Adsorption Isotherms}

Adsorption isotherms are applied to describe the equilibrium of adsorbate fraction between solid and liquid phases. Freundlich and Langmuir are the most common isotherm models used for liquid adsorption systems. Moreover, ten other isotherm models that are less commonly used in adsorption studies were employed in the current research. Figure 7 depicts the experimental equilibrium data fitted to the Freundlich and Langmuir equations. The equation parameters and statistical indices for all adsorption isotherms are summarized in Table 3. As indicated, the Freundlich and Halsey equations generated a similar fit quality, and they were the most adequate twoparameter models for describing the behavior of the system by giving the lowest $\chi^{2}$, SSE, and AIC and the highest $\mathrm{Adj}$. $\mathrm{R}^{2}$ values. However, the Langmuir equation also showed a reasonable fit by giving a calculated $\mathrm{q}_{\mathrm{m}}(75.23 \mathrm{mg}$ $\mathrm{g}^{-1}$ ) close to the maximum experimental value $(78.75 \mathrm{mg}$ $\left.\mathrm{g}^{-1}\right)$. The $\mathrm{b}$ constant in the Langmuir equation was used to compute the separation factor, $\mathrm{R}_{\mathrm{L}}$, from the following equation:

$$
R_{L}=\frac{1}{1+b C_{0}}
$$

where $\mathrm{C}_{0}\left(\mathrm{mg} \mathrm{L}^{-1}\right)$ is the highest initial concentration of adsorbate. Given $\mathrm{C}_{0}=500 \mathrm{mg} \mathrm{L}^{-1}$ in the isotherm studies, $\mathrm{R}_{\mathrm{L}}$ $=0.06$ was obtained, which indicates a favorable adsorption because of $0<\mathrm{R}_{\mathrm{L}}<1$.

Jovanovic isotherm, as a two parameter model, gave the poorest fit with the experimental data of this study. Three isotherms, including Hill, Sips, and Koble-Corrigan were the most efficient three-parameter models to fit the data. On the other hand, the Brunauer-Emmett-Teller (BET) isotherm was the poorest model examined in this study for prediction of equilibrium state in the phenol-silica aerogel system. The parameters of models and statistical indices for other isotherm models are listed in Table 3.

\section{Discussion}

\subsection{Characterization of Silica Aerogel}

In terms of morphology, SEM examination showed that silica aerogel has a rough surface composed of an interconnected network. The pore sizes are different, including macropores (50 to $1000 \mathrm{~nm}$ ), mesopores (2 to $50 \mathrm{~nm}$ ), and micropores ( 0.2 to $2 \mathrm{~nm}$ ). Faghihian et al. (14) also defined the surface of prepared silica aerogel inconsistent and heterogeneous. 
A

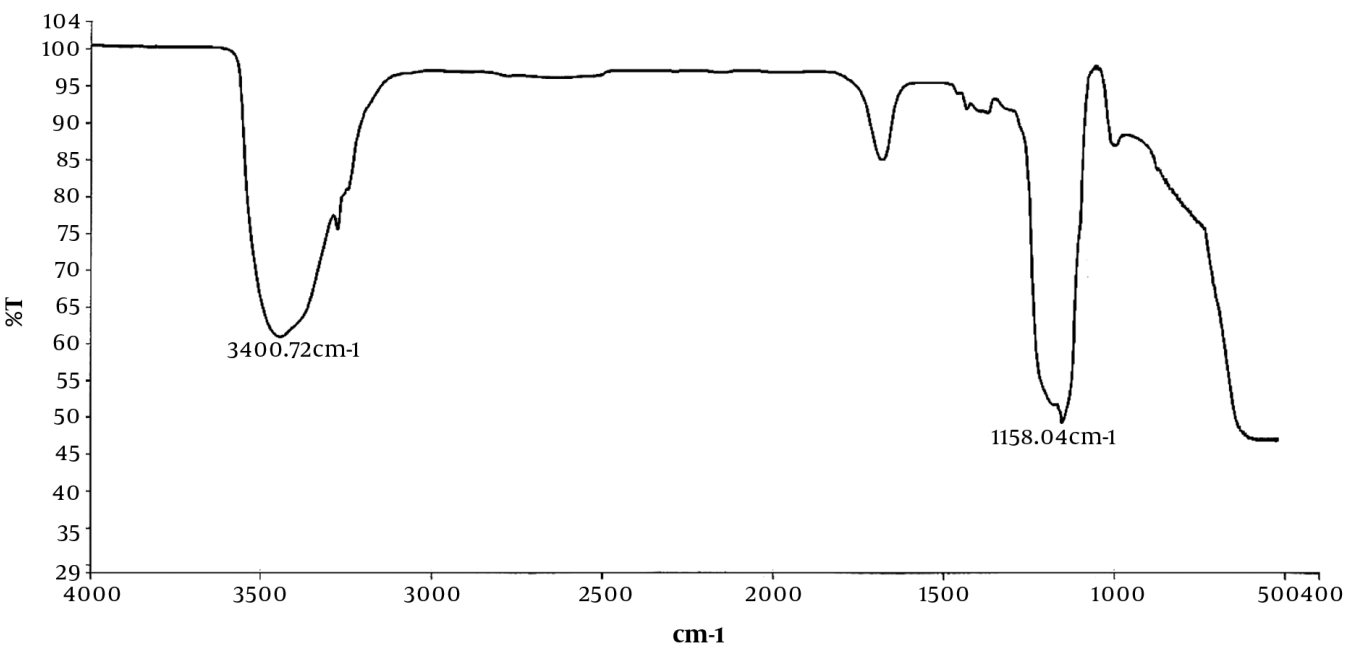

B

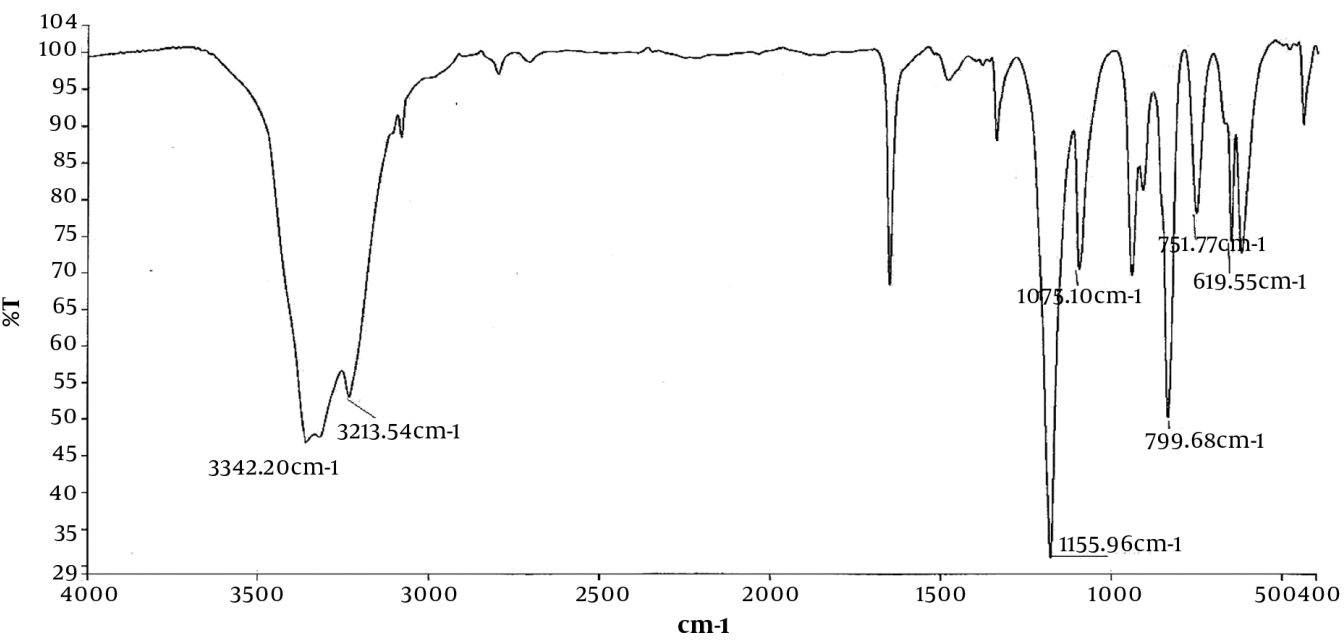

Figure 3. FTIR spectra before phenol adsorption (A) and after phenol adsorption (B)

Table 2. Kinetic Parameters for the Adsorption of Phenol onto Silica Aerogel

\begin{tabular}{|c|c|c|c|c|c|c|c|}
\hline \multirow{2}{*}{ Kinetic Model } & \multirow{2}{*}{ Concentration $\left(\mathrm{mg} \mathrm{L}^{-1}\right)$} & \multirow{2}{*}{ Experimental $q_{\mathrm{e}}\left(\mathrm{mg} \mathrm{g}^{-1}\right)$} & \multicolumn{2}{|c|}{ Model Parameters } & \multicolumn{3}{|c|}{ Statistical Indices } \\
\hline & & & $q_{e}\left(m g^{-1}\right)$ & $\mathbf{k}$ & $\chi^{2}$ & SSE & Adj. $R^{2}$ \\
\hline \multirow{2}{*}{ Pseudo-first order } & 50 & 23.95 & 25.10 & 0.043 & 3.61 & 25.28 & 0.9641 \\
\hline & 100 & 40.60 & 42.37 & 0.025 & 5.01 & 35.07 & 0.9807 \\
\hline \multirow{2}{*}{ Pseudo-second order } & 50 & 23.95 & 29.67 & $1.6 \mathrm{E}^{-3}$ & 7.89 & 55.23 & 0.9215 \\
\hline & 100 & 40.60 & 53.76 & $0.4 \mathrm{E}^{-3}$ & 10.02 & 70.14 & 0.9614 \\
\hline
\end{tabular}

According to the XRD pattern of silica aerogel in Figure 2 that shows a broad peak close to $20^{\circ}(2 \theta)$, the amorphous structure of $\mathrm{SiO}_{2}$ was confirmed. This finding is consistent with the obtained results by Thompson et al. (29) and Poureteda et al. (30).

The characterization of silica aerogel in FTIR spectra
(Figure 3) indicated the disposition of hydroxyl group into silicate network, which turns sodium silicate to aerogel. After phenol adsorption, a peak shifted to $3342 \mathrm{~cm}^{-1}$ and a new one appeared at $3213 \mathrm{~cm}^{-1}$, which demonstrated the contribution of -OH functional group in the phenol uptake. The greater intensity of O-Si-O peak in the spectrum of 
A

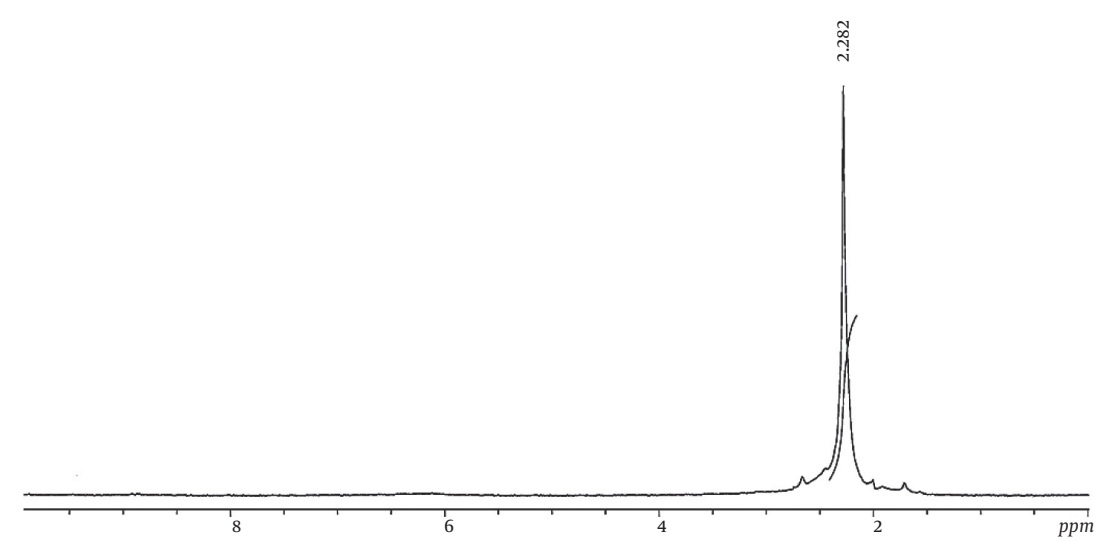

B

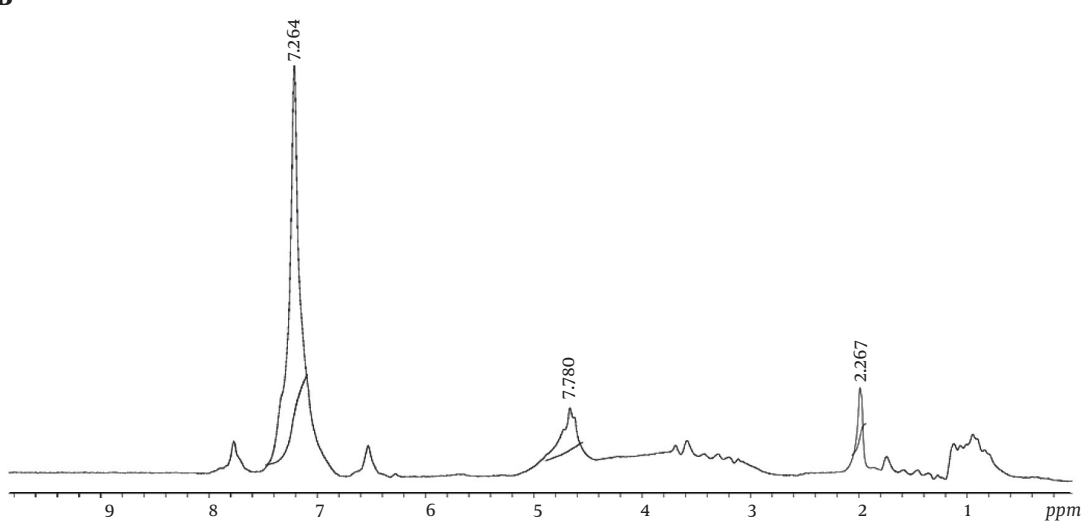

Figure 4. NMR spectrum before phenol adsorption (A) and after phenol adsorption (B)

\begin{tabular}{|c|c|c|c|c|c|}
\hline \multirow[t]{2}{*}{ Isotherm } & \multicolumn{5}{|c|}{ BR46 Isotherm Parameters } \\
\hline & Constants & $\chi^{2}$ & SSE & Adj. $R^{2}$ & AIC \\
\hline Langmuir & $\mathrm{b}=0.06 \mathrm{~L} \mathrm{mg}^{-1}, \mathrm{q}_{\mathrm{m}}=75.23 \mathrm{mg} \mathrm{g}^{-1}$ & 37.45 & 299.64 & 0.9463 & 44.00 \\
\hline Freundlich & $\mathrm{K}_{\mathrm{f}}=17.22\left(\mathrm{mg} \mathrm{g}^{-1}\right)\left(\mathrm{L} \mathrm{g}^{-1}\right)^{1 / \mathrm{n}}, \mathrm{n}=3.73$ & 11.78 & 94.21 & 0.9831 & 32.43 \\
\hline Jovanovic & $\mathrm{q}_{\mathrm{m}}=67.99 \mathrm{mg} \mathrm{g}^{-1}, \mathrm{~K}_{\mathrm{j}}=-0.046 \mathrm{~L} \mathrm{mg}^{-1}$ & 68.98 & 551.84 & 0.9011 & 50.11 \\
\hline Halsey & $\mathrm{K}_{\mathrm{H}}=2.4 \mathrm{E}-5, \mathrm{n}_{\mathrm{H}}=-3.74$ & 11.78 & 94.21 & 98.31 & 32.43 \\
\hline Hill & $\mathrm{q}_{\mathrm{SH}}=134.07 \mathrm{mg} \mathrm{L}^{-1}, \mathrm{~K}_{\mathrm{D}}=8.66, \mathrm{n}_{\mathrm{H}}=0.432$ & 7.01 & 49.10 & 0.9899 & 31.91 \\
\hline Sips & $\mathrm{K}_{\mathrm{S}}=15.48 \mathrm{Lg}^{-1}, \mathrm{~A}_{\mathrm{S}}=0.11 \mathrm{~L} \mathrm{mg}^{-1}, \mathrm{~B}_{\mathrm{S}}=0.432$ & 7.01 & 49.10 & 0.9899 & 31.91 \\
\hline Koble-Corrigan & $\mathrm{a}=15.49 \mathrm{~L}^{\mathrm{n}} \mathrm{mg}^{1-\mathrm{n}} \mathrm{g}^{-1}, \mathrm{~b}=0.115\left(\mathrm{~L} \mathrm{mg}^{-1}\right)^{\mathrm{n}}, \mathrm{n}=0.432$ & 7.01 & 49.10 & 0.9899 & 31.91 \\
\hline Toth & $\mathrm{K}_{\mathrm{T}}=21.76 \mathrm{mg} \mathrm{g}^{-1}, \mathrm{~A}_{\mathrm{T}}=1.38 \mathrm{~L} \mathrm{mg}^{-1}, \mathrm{~T}=1.29$ & 15.19 & 106.32 & 0.9782 & 39.64 \\
\hline Redlich-Peterson & $\mathrm{k}_{\mathrm{RP}}=28.24 \mathrm{~L} \mathrm{~g}^{-1}, \mathrm{a}_{\mathrm{RP}}=1.27\left(\mathrm{mg} \mathrm{L}^{-1}\right)^{-\mathrm{bRP}}, \mathrm{b}_{\mathrm{RP}}=0.778$ & 13.81 & 96.65 & 0.9802 & 38.68 \\
\hline Radke-Prausnitz & $\mathrm{a}_{\mathrm{RP}}=28.21, \mathrm{r}_{\mathrm{R}}=22.19, \mathrm{~B}_{\mathrm{R}}=0.22$ & 13.81 & 96.65 & 0.9802 & 38.68 \\
\hline Khan & $\mathrm{q}_{\mathrm{s}}=3.59 \mathrm{mg} \mathrm{g}^{-1}, \mathrm{~b}_{\mathrm{K}}=355.28, \mathrm{a}_{\mathrm{K}}=0.732$ & 13.46 & 94.19 & 0.9807 & 38.42 \\
\hline Bet & $\mathrm{C}_{\mathrm{BET}}=158.53 \mathrm{~L} \mathrm{mg}^{-1}, \mathrm{q}_{\mathrm{s}}=59.09 \mathrm{mg} \mathrm{g}^{-1}, \mathrm{Cs}=1267.14 \mathrm{mg} \mathrm{L}^{-1}$ & 24.18 & 169.27 & 0.9653 & 44.29 \\
\hline
\end{tabular}

phenol-loaded adsorbent implied a better developed silica network after phenol adsorption (31).

In the NMR spectra, illustrated in Figure 4, a chemical shift around $2.2 \delta$ appeared, which can be referenced to Si$\mathrm{OH}$ (27). The weak chemical shift observed at $4.7 \delta$ in the spectrum after adsorption was probably due to the pheno- 
A

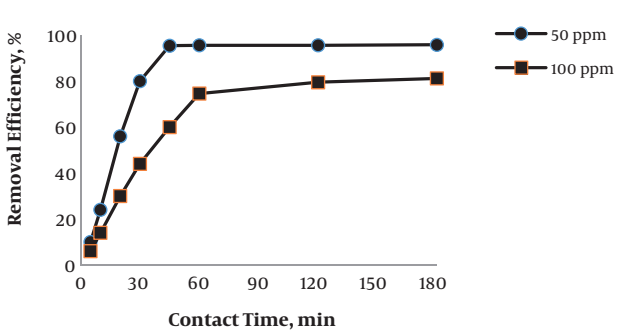

C

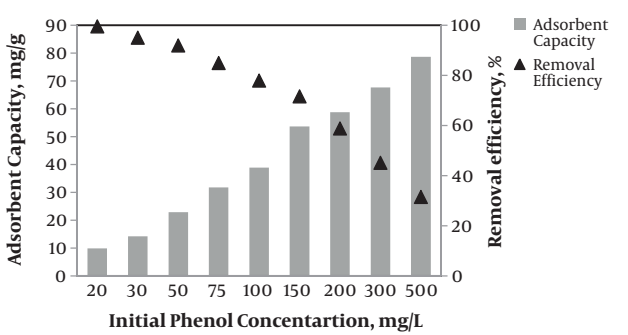

B

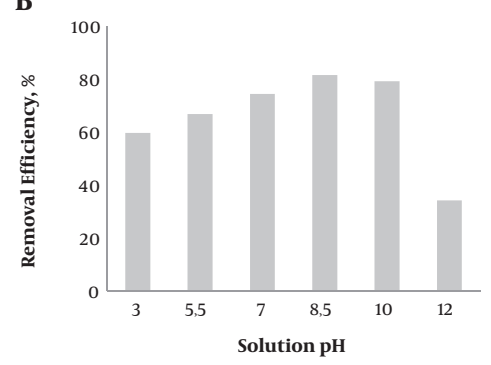

D

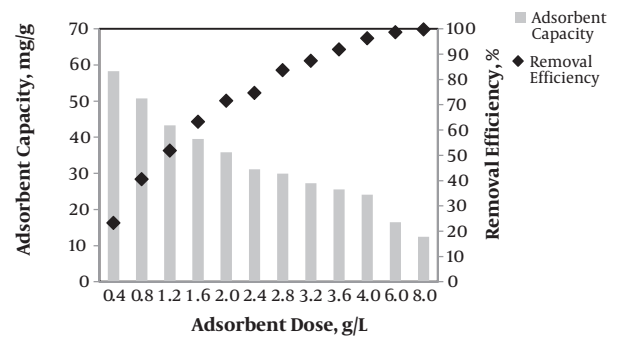

Figure 5. Adsorption of phenol onto silica aerogel as a function of: A, contact time (silica aerogel dose $=2 \mathrm{~g} \mathrm{~L}^{-1}$, solution $\mathrm{pH}=7$ ); $\mathrm{B}$, solution $\mathrm{pH}$ (initial phenol $=100 \mathrm{mg} \mathrm{L^{-1 }}$ silica aerogel $=2 \mathrm{~g} \mathrm{~L}^{-1}$, contact time $=60 \mathrm{~min}$ ); $\mathrm{C}$, initial concentration of phenol (silica aerogel $=2 \mathrm{~g} \mathrm{~L}^{-1}$, contact time $=60 \mathrm{~min}$, solution pH $=7$ ); and $\mathrm{D}$, adsorbent dose (initial phenol $=100 \mathrm{mg} \mathrm{L}^{-1}$, solution $\mathrm{pH}=7$, contact time $=60 \mathrm{~min}$ )

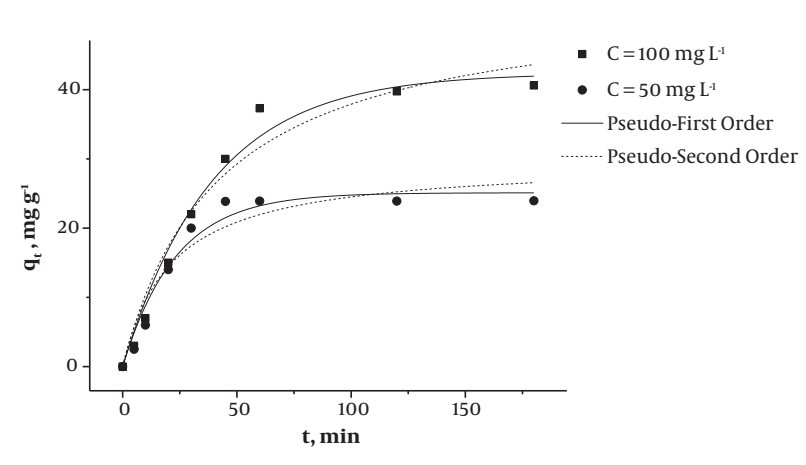

Figure 6. The non-linear plots of kinetics for phenol adsorption onto silica aerogel $\left(\mathrm{pH}=8.5\right.$, silica aerogel $\left.=2 \mathrm{~g} \mathrm{~L}^{-1}\right)$

lic -OH group and the chemical shift in the region of $7.2 \delta$ can be attributed to phenolic aromatic ring (32). They both indicated adsorption of phenol onto the surface of silica aerogel.

Determination of pHzpc at 6.9 reveals that surface sorption sites of adsorbent are positively charged at medium $\mathrm{pH}$ below 6.9, neutral at $\mathrm{pH}$ equal to 6.9, and negatively charged at $\mathrm{pH}$ above 6.9. The $\mathrm{pHzpc}$ value around neutral $\mathrm{pH}$ has also been reported for silica aerogel in other studies (33).

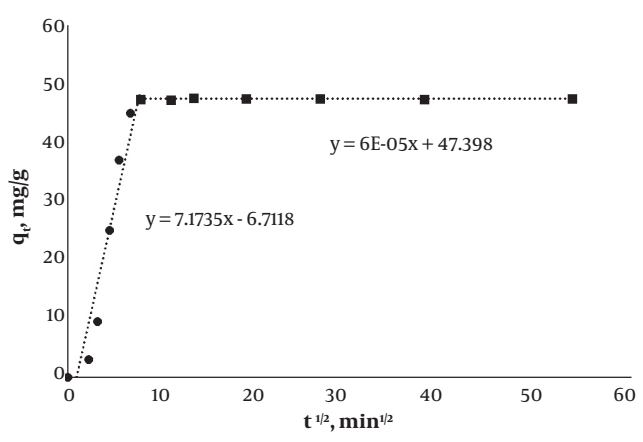

Figure 7. Intraparticle diffusion plot for adsorption of phenol onto silica aerogel (Initial phenol $=100 \mathrm{mg} \mathrm{L}^{-1}, \mathrm{pH}=8.5$, silica aerogel $=2 \mathrm{~g} \mathrm{~L}^{-1}$ )

\subsection{Effect of Contact Time}

As mentioned earlier, to determine the effect of contact time on the adsorption process, the experiments were carried out at two different initial concentrations of phenol. As observed in Figure $5 \mathrm{~A}$, the removal rate was higher in the presence of lower phenol concentration ( $95.8 \%$ versus $81.2 \%$ at 50 and $100 \mathrm{mgL}^{-1}$, respectively). The obtained results of this study is in accordance with the findings of Rodrigues et al. (34). The high removal rate of phenol during the first one-third of reaction time was attributed to the interfacial bonding of adsorbate on the empty and readyto-adsorb binding sites of adsorbent surface (35). In a pre- 


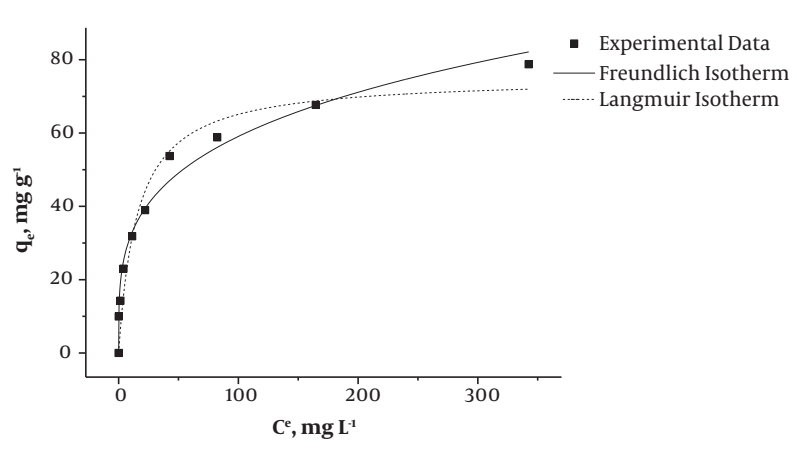

Figure 8. Equilibrium adsorption isotherms for phenol adsorption on silica aerogel (initial phenol $=20-500 \mathrm{mg} \mathrm{L}^{-1}, \mathrm{pH}=8.5$, silica aerogel $=2 \mathrm{~g} \mathrm{~L}^{-1}$, contact time $=180$ min)

vious study, a removal efficiency of $60 \%$ was obtained for phenol $(20 \mathrm{mg} / \mathrm{L})$ in the presence of Luffa cylindrica fibers as adsorbent at 120 minutes of contact time (36).

\subsection{Effect of Solution $\mathrm{pH}$}

Solution $\mathrm{pH}$ is one of the most effective parameters in the adsorption process because it directly affects ionization degree of solute and surface characteristics of adsorbent. As shown in Figure 5 B, the maximum removal rate was attained at $\mathrm{pH}$ 8.5. The effect of solution $\mathrm{pH}$ observed in the present study is similar to that observed by Abdelwahab and Amin (36) in a phenol adsorption system. To explain the findings, it should be noted that phenol as a weak acid has a $\mathrm{pK}_{\mathrm{a}}$ value around 10 , which means that this molecule is predominantly found as phenoxide ion (the anionic form of phenol) at $\mathrm{pH}$ values above 10 (34). At the same time, due to the pHzpc of 6.9, silica aerogel also has negative sites on the surface. Therefore, in this $\mathrm{pH}$ region, electrostatic repulsive force between anions of phenoxide and negatively charged silica aerogel hindered the adsorption of solute onto the adsorbent. On the other hand, in media with $\mathrm{pH}$ below 10 , phenol remained in its undissociated form, which could be attracted by negative $(6.9<\mathrm{pH}<$ $10)$, neutral ( $\mathrm{pH}=6.9)$, and positive $(3<\mathrm{pH}<6.9)$ surface of silica aerogel due to dispersion interaction. The lower removal rate at $\mathrm{pH} \leq 5.5$ could be attributed to the competition of protons with phenol molecules to be adsorbed onto silica aerogel surface (35).

\subsection{Effect of Initial Concentration of Phenol}

The initial concentration of solute is of remarkable importance due to its role in the solid/liquid equilibrium. In this study, the reduction in the removal efficiency at higher phenol concentrations (Figure $5 \mathrm{C}$ ) could be due to the saturation of active sites of the adsorbent, which resists against phenol molecules uptake at high concentrations.
On the other hand, a decrease in the adsorption capacity of silica aerogel was observed by decreasing phenol concentration in the solution. This trend has been previously reported in similar studies (35) and indicated unsaturated adsorption sites on silica aerogel surface in presence of low concentrations of phenol. In general, the adsorption process using silica aerogel synthetized in this study could remove phenol over 90\% when initial phenol concentration was below $50 \mathrm{mg} \mathrm{L}^{-1}$. In comparison with other treatment processes for phenol removal, Davoudi et al. (8) reported removal rate of $78.14 \%$ in an electrochemical oxidation process, Asgari et al. (4) obtained the rate of $32 \%$ in sole ozonation process and $63 \%$ in catalytic ozonation process with modified zeolite, and Bazrafshan et al. (37) suggested efficiencies of $94.72 \%$ and $98 \%$ in electrocoagulation process with aluminum and iron electrodes, respectively.

\subsection{Effect of Silica Aerogel Dosage}

Different adsorbent dosages have an impact on the number of adsorption sites available for the adsorbate. According to Figure $5 \mathrm{D}$, adsorbent has a significant direct effect on the removal rate. The trend in this study can be related to the increased surface area and active sites of adsorbent in high applied doses of adsorbent. On the contrary, the loaded amount of phenol decreased by an increase in adsorbent dosage. This trend has also been reported by Rodrigues et al. (34) for removal of phenol by using carbon xerogel. A removal efficiency of $65 \%$ was obtained by Abdelwahab and Amin in presence of $3 \mathrm{~g} / \mathrm{L}$ Luffa cylindrica fibers at $20 \mathrm{mg} / \mathrm{L}$ of phenol (36).

\subsection{Adsorption Kinetics}

Kinetics of adsorption were examined at two phenol concentrations of 50 and $100 \mathrm{mg} \mathrm{L}^{-1}$. The obtained results (Figure 6 and Table 2 ) indicated that the experimental data were better predicted by the pseudo-first order kinetic equation than pseudo-second order kinetic equation. This finding indicates the contribution of physical adsorption of phenol molecules onto silica aerogel was probably due to the driving force in presence of high initial concentrations (38).

The intra-particle diffusion was also investigated in the current study. As indicated by Figure 7, two lines with different slopes are distinguishable. From the first line that describes the adsorption process in the initial 60 minutes of the reaction, $\mathrm{k}_{\mathrm{id}}$ is $7.1735 \mathrm{mg}\left(\mathrm{g} \mathrm{min}^{1 / 2}\right)^{-1}$ and $\mathrm{C}$ constant is $6.7118 \mathrm{mg} \mathrm{g}^{-1}$. The $\mathrm{C}$ constant is of importance because it is proportional to the thickness of boundary layer in the interface of liquid-solid (39). The second line describes the behavior of the system between the reaction times of 60 and 2880 minutes. As observed, the slope of the line 
( $\mathrm{k}_{\mathrm{id}}$ value) is quite close to zero $\left(=6 \mathrm{E}^{-5}\right)$ indicating that the system had reached an equilibrium. Under such circumstances, the amount of phenol adsorbed on $1 \mathrm{~g}$ of adsorbent (i.e. C constant value) was fixed at $47.398 \mathrm{mg} \mathrm{g}^{-1}$. In the literature, a single-step reaction was reported by Doltabadi et al. (20) for adsorption of cationic and anionic dyes onto sawdust-based adsorbent and a three-step plot was drawn by Witek-Krowiak for adsorption of malachite green onto beech sawdust (40).

\subsection{Adsorption Isotherms}

As previously mentioned for the isotherm study, the experimental equilibrium data were well-described by Freundlich and Halsey equations. This finding is in accordance with the finding of a previous study (23) and may be due to the fact that both models have been developed to explain multilayer coverage of adsorption of molecules onto an adsorbent with heterogeneous sorption sites. Similar to the current study, Qin et al. (12) introduced the Freundlich isotherm as the best adequate model in phenolgranular silica aerogel system, supporting the idea of physical adsorption of phenol on silica aerogel surface. A value of $n>1$ in the Freundlich model shows the favorable adsorption of phenol onto silica aerogel (41). The maximum adsorption capacity of silica aerogel was found to be 75.23 $\mathrm{mg} \mathrm{g}^{-1}$ in this study from the Langmuir equation, which is smaller than that reported by Abdoli et al. (35) for uptake of 4-Bromophenol (270.27 $\mathrm{mg} \mathrm{g}^{-1}$ ) and 4-Chlorophenol (238.09 $\mathrm{mg} \mathrm{g}^{-1}$ ) on nanoporous silica aerogel, while it is higher than the capacity of $32 \mathrm{mg} \mathrm{g}^{-1}$ observed by Rodrigues et al. (34) for adsorption of phenol onto carbon xerogel. Furthermore, in Faghihian et al. study, the maximum adsorption capacity of the modified silica aerogel was obtained as $47.6 \mathrm{mg} / \mathrm{g}$ for $\mathrm{Cu}(\mathrm{II})$ and $27.7 \mathrm{mg} / \mathrm{g}$ for $\mathrm{Ni}(\mathrm{II})$ (14), which is much smaller than what was obtained in this study. Regarding phenol adsorption on other adsorbents, Gokce and Aktas (42) reported adsorption capacity of 108.4 $\mathrm{mg} / \mathrm{g}$ for activated carbon produced from waste tea, Han et al. (43) reported $36.2 \mathrm{mg} / \mathrm{g}$ for a functionalized porous material (PGMA), and Abdelwahab and Amin (36) obtained $10.37 \mathrm{mg} / \mathrm{g}$ for Luffa cylindrica fibers.

The reason for poor fitting of Jovanovich isotherm could be due to the fact that this equation is developed on the basic assumption of monolayer adsorption (22). Hence, it can be concluded that adsorption of phenol on silica aerogel could not be described as monolayer localized, specially without lateral interactions assumed by the Jovanovic isotherm.

Among three-parameter models, three isotherms of Hill, Sips, and Koble-Corrigan gave better fits with the data, which is in accordance with a previous study (44). As indicated, Hill, Sips, and Koble-Corrigan isotherms overlapped each other by producing similar values of statistical indices. This finding is in line with those reported by Doltabadi et al. (20) for removal of BR46 and RR196 dyes, using sawdust adsorbent. However, different values have been obtained in the statistical analysis of aforementioned models by Najafpoor et al. (41) for description of RR141 uptake on Melia sawdust. The Hill isotherm postulates that homogenous surface sites are responsible for adsorption of species. The Sips and Koble-Corrigan isotherms, however, have been written by combining the Langmuir and Freundlich models to overcome the limitation associated with rising pollutant concentration in the Freundlich isotherm. Sips can reasonably predict the monolayer adsorption capacity characterized by the Langmuir isotherm in presence of high concentrations of adsorbate; while at low concentrations, it approaches multilayer adsorption capacity similar to the Freundlich model.

The Toth isotherm has been developed to improve the traditional Langmuir isotherm. This model is useful for representation of the equilibrium data in heterogeneous adsorption systems. However, the Toth model could not explain the experimental data under the conditions of the current study.

Another isotherm model incorporating both Langmuir and Freundlich equations is the Redlich- Peterson model. This model is applicable for a wide range of adsorbate concentrations in homogeneous or heterogeneous kinds of adsorption systems. In the current study, it was somewhat efficient for prediction of experimental data because of giving Adj. $\mathrm{R}^{2}$ value of 0.9802 and AIC value of 38.68. Similar values were also calculated in case of the Radke-Prausnitz model, which is consistent with the findings of Hamdaoui and Naffrechoux (45) for adsorption of phenol and chlorophenols onto granular activated carbon.

Khan isotherm, suggested for pure solutions, also generated a reasonably good fit with the equilibrium adsorption data. Brunauer-Emmett-Teller (BET) isotherm gave the poorest outputs probably due to the fact that this isotherm is suitable for gas-solid systems while the current research dealt with phenol adsorption in a liquid system.

Data on the cost of adsorbents used for phenol removal are scarce in scientific articles. Silica aerogel is not an exception as well. It is believed that the cost of adsorbent depends on factors, such as its availability, materials used for processing, applied experimental conditions, recyclability, etc. In terms of cost-effectiveness, there is a rule of thumb that low-cost adsorbents have low adsorption capacities and vice versa. For instance, the adsorption capacities of 23.8, 59.2, and $350 \mathrm{mg} / \mathrm{g}$ were obtained for phenol removal by using Bagasse fly ash (cost: 20 US\$/ton), Red mud (25 US\$/ton), and Activated carbon (22000 US\$/ton), respec- 
tively. By comparing the results, silica aerogel used in this study was more efficient (75.23 $\mathrm{mg} \mathrm{g}^{-1}$ adsorption capacity) than Bagasse fly ash and Red mud and less efficient than activated carbon (46).

\subsection{Conclusion}

In this study, silica aerogel was prepared, characterized, and successfully used for phenol adsorption in a wide range of concentration (20 to $500 \mathrm{mg} \mathrm{L}^{-1}$ ). The removal efficiency reached above $90 \%$ for concentrations equal to or below $50 \mathrm{mg} \mathrm{L}^{-1}$. The equilibrium time also showed a relationship with initial phenol concentration as it decreased by decreasing initial concentration. The reaction kinetics followed the pseudo-first order model. The isotherm study showed that equilibrium adsorption data were well-described by Freundlich and Halsey equations, among two-parameter isotherms, and Hill, Sips, and KobleCorrigan, among three-parameter isotherms. On the other hand, Jovanovic and BET were the worst isotherm models for prediction of experimental equilibrium data. Maximum adsorption capacity of $75.23 \mathrm{mg} \mathrm{g}^{-1}$ was calculated in the phenol-silica aerogel adsorption system. The chemical structural analysis confirmed -OH functional groups in amorphous $\mathrm{SiO}_{2}$ and proved the adsorption of phenol onto the surface of silica aerogel. It can be concluded that silica aerogel is an efficient adsorbent for removal of phenol from aqueous solutions and can be used for industrial wastewater treatment.

\section{Acknowledgments}

This study was carried out thanks to the technical and financial support of the Vice Chancellor for Research and the Research Center for Health Sciences of Hamadan University of Medical Sciences. The authors of the manuscript do not have any relationship with the commercial identities mentioned in the manuscript.

\section{Footnotes}

Authors' Contribution: The first and second authors have the same contribution. Alireza Rahmani and Fateme Nazemi equally participated in designing the study, conducting experiments, and analyzing the data. Also, Fateme Barjasteh Askari and Mojtaba Davoudi wrote and critically revised the manuscript.

Funding/Support: This research was financially supported by Hamadan University of Medical Sciences, Hamadan, Iran.

\section{References}

1. Saravanan P, Pakshirajan K, Saha P. Growth kinetics of an indigenous mixed microbial consortium during phenol degradation in a batch reactor. Bioresour Technol. 2008;99(1):205-9. doi: 10.1016/j.biortech.2006.11.045. [PubMed:17236761].

2. Babuponnusami A, Muthukumar K. Advanced oxidation of phenol: a comparison between fenton, electro-fenton, sono-electro-fenton and photo-electro-fenton processes. Chem Eng J. 2012;183:1-9. doi: 10.1016/j.cej.2011.12.010.

3. Schueller BS, Yang RT. Ultrasound enhanced adsorption and desorption of phenol on activated carbon and polymeric resin. Ind Eng Chem Res. 2001;40(22):4912-8. doi:10.1021/ie010490j.

4. Asgari G, Rahmani AR, Barjasteh Askari F, Godini K. Catalytic ozonation of phenol using copper coated pumice and zeolite as catalysts. $J$ Res Health Sci. 2012;12(2):93-7. [PubMed: 23241518].

5. Golbaz S, Jonidi Jafari A, Rafiee M, Rezaei Kalantary R. Separate and simultaneous removal of phenol, chromium, and cyanide from aqueous solution by coagulation/precipitation: Mechanisms and theory. Chem Eng J. 2014;253:251-7. doi: 10.1016/j.cej.2014.05.074.

6. Nakhli SAA, Ahmadizadeh K, Fereshtehnejad M, Rostami MH, Safari M, Borghei SM. Biological removal of phenol from saline wastewater using a moving bed biofilm reactor containing acclimated mixed consortia. Springerplus. 2014;3:112. doi: 10.1186/2193-1801-3-112. [PubMed: 24616843]. [PubMed Central: PMC3946108].

7. Bazrafshan E, Kord Mostafapour F, Mahvi AH. Phenol removal from aqueous solutions using pistachio-nut shell ash as a low cost adsorbent. Fresenius Environ Bull. 2012;21:2962-8.

8. Davoudi M, Gholami M, Naseri S, Mahvi AH, Farzadkia M, Esrafili A, et al. Application of electrochemical reactor divided by cellulosic membrane for optimized simultaneous removal of phenols, chromium, and ammonia from tannery effluents. Toxicol Environ Chem. 2014;96(9):1310-32. doi: 10.1080/02772248.2014.942311.

9. Bazrafshan E, Biglari H, Mahvi AH. Phenol removal by electrocoagulation process from aqueous solutions. Fresenius Environ Bull. 2012;21(2):364-71.

10. Venkateswara Rao A, Hegde ND, Hirashima H. Absorption and desorption of organic liquids in elastic superhydrophobic silica aerogels. J Colloid Interface Sci. 2007;305(1):124-32. doi: 10.1016/j.jcis.2006.09.025. [PubMed: 17067617].

11. Liu H, Sha W, Cooper AT, Fan M. Preparation and characterization of a novel silica aerogel as adsorbent for toxic organic compounds. Colloid Surface A Physicochem Eng Aspect. 2009;347(1-3):38-44. doi: 10.1016/j.colsurfa.2008.11.033.

12. Qin G, Yao Y, Wei W, Zhang T. Preparation of hydrophobic granular silica aerogels and adsorption of phenol from water. Appl Surf Sci. 2013;280:806-11. doi: 10.1016/j.apsusc.2013.05.066.

13. Bangi UKH, Jung I-K, Park C-S, Baek S, Park H-H. Optically transparent silica aerogels based on sodium silicate by a two step sol-gel process and ambient pressure drying. Solid State Sci. 2013;18:50-7. doi: 10.1016/j.solidstatesciences.2012.12.016.

14. Faghihian H, Nourmoradi H, Shokouhi M. Removal of copper (II) and nickel (II) from aqueous media using silica aerogel modified with amino propyl triethoxysilane as an adsorbent: equilibrium, kinetic, and isotherms study. Desalin Water Treat. 2013;52(1-3):305-13. doi: 10.1080/19443994.2013.785367.

15. Standeker S, Novak Z, Knez Z. Removal of BTEX vapours from waste gas streams using silica aerogels of different hydrophobicity. $J$ Hazard Mater. 2009;165(1-3):1114-8. doi: 10.1016/j.jhazmat.2008.10.123. [PubMed: 19095355].

16. Gurav JL, Jung I-K, Park H-H, Kang ES, Nadargi DY. Silica aerogel: Synthesis and applications. J Nanomaterials. 2010;2010:1-11. doi: $10.1155 / 2010 / 409310$.

17. Katagiri N, Ishikawa M, Adachi N, Fuji M, Ota T. Preparation and evaluation of Au nanoparticle-silica aerogel nanocomposite. J Asian Ceram Soc. 2015;3(2):151-5. doi: 10.1016/j.jascer.2015.01.003. 
18. Soleimani Dorcheh A, Abbasi MH. Silica aerogel; synthesis, properties and characterization.JMater Process Tech.2008;199(1-3):10-26. doi: 10.1016/j.jmatprotec.2007.10.060.

19. Dastgheib SA, Karanfil T, Cheng W. Tailoring activated carbons for enhanced removal of natural organic matter from natural waters. Carbon. 2004;42(3):547-57. doi:10.1016/j.carbon.2003.12.062.

20. Doltabadi M, Alidadi $H$, Davoudi M. Comparative study of cationic and anionic dye removal from aqueous solutions using sawdust-based adsorbent. Environ Progr Sustain Energ. 2016. doi: 10.1002/ep.12334.

21. Foo KY, Hameed BH. Insights into the modeling of adsorption isotherm systems. Chem Eng J. 2010;156(1):2-10. doi: 10.1016/j.cej.2009.09.013.

22. Samarghandi MR, Hadi M, Moayedi S, Barjesteh Askari F. Twoparameter isotherms of methyl orange sorption by pinecone derived activated carbon. Iranian J Environ Health Sci Eng. 2009;6(4):285-94.

23. Neto VOS, Oliveira AG, Teixeira RNP, Silva MAA, Freire PCT, De Keukeleire D, et al. Use of coconut bagasse as alternative adsorbent for separation of copper (II) ions from aqueous solutions: isotherms, kinetics, and thermodynamic studies. BioResources. 2011;6(3):3376-95.

24. Water Environment Federation; American Public Health Association. Standard methods for the examination of water and wastewater. 22th ed. Washington DC, USA: American Public Health Association (APHA); 2005.

25. Tadjarodi A, Haghverdi M, Mohammadi V, Rajabi M. Synthesis and characterization of hydrophobic silica aerogel by two step (acid-base) sol-gel process. J Nanostruct. 2013;3(2):181-9. doi: 10.7508/jns.2013.02.006.

26. Shokri B, Firouzjah MA, Hosseini S, editors. FTIR analysis of silicon dioxide thin film deposited by metal organic-based PECVD. Proceedings of 19th international symposium on plasma chemistry society. Bochum, Germany. 2009.

27. El Rassy H, Pierre AC. NMR and IR spectroscopy of silica aerogels with different hydrophobic characteristics. J Non-Crystalline Solids. 2005;351(19-20):1603-10. doi: 10.1016/j.jnoncrysol.2005.03.048.

28. Poznyak T, Vivero J. Degradation of aqueous phenol and chlorinated phenols by ozone. Ozone Sci Eng. 2005;27(6):447-58. doi: 10.1080/01919510500351529.

29. Thompson SP. Structural signatures of medium-range order in annealed laboratory silicates. Astron Astrophys. 2008;484(1):251-65. doi: 10.1051/0004-6361:20078675.

30. Pouretedal HR, Kazemi M. Characterization of modified silica aerogel using sodium silicate precursor and its application as adsorbent of $\mathrm{Cu} 2+, \mathrm{Cd} 2+$, and Pb2+ ions. Int J Ind Chem. 2012;3(1):20. doi: 10.1186/2228-5547-3-20.

31. Al-Oweini R, El-Rassy H. Synthesis and characterization by FTIR spectroscopy of silica aerogels prepared using several $\mathrm{Si}(\mathrm{OR}) 4$ and $\mathrm{R}^{\prime \prime} \mathrm{Si}\left(\mathrm{OR}^{\prime}\right) 3$ precursors. J Mol Struct. 2009;919(1-3):140-5. doi: 10.1016/j.molstruc.2008.08.025.

32. Thenmozhi G, Jaya Kumar D, Mohanraj G, Jaya Santhi R. Synthesis, characterization and biological applications of poly meta amino phe- nol and its nano compound. Der Pharma Chemica. 2011;3(6):325-33.

33. Malinowska B, Walendziewski J, Robert D, Weber JV, Stolarski M. The study of photocatalytic activities of titania and titania-silica aerogels. Appl Catal B Environ. 2003;46(3):441-51. doi: 10.1016/s09263373(03)00273-x.

34. Rodrigues LA, Campos TMB, Alvarez-Mendes MO, dos Reis Coutinho A, Sakane KK, Thim GP. Phenol removal from aqueous solution by carbon xerogel. J Sol-Gel Sci Tech. 2012;63(2):202-10. doi: 10.1007/s10971012-2745-3.

35. Abdoli SM, Bastani D, Bargozin H. Adsorption of phenol compounds by nanoporous silica aerogel. Scientia Iranica. Transaction $C$, Chem, Chem Eng. 2015;22(3):992.

36. Abdelwahab O, Amin NK. Adsorption of phenol from aqueous solutions by Luffa cylindrica fibers: Kinetics, isotherm and thermodynamic studies. Egypt J Aquat Res. 2013;39(4):215-23. doi: 10.1016/j.ejar.2013.12.011.

37. Bazrafshan E, Biglari H, Mahvi AH. Performance evaluation of electrocoagulation process for phenol removal from aqueous solutions. Fresenius Environ Bull. 2012;21:364-71.

38. Sener S. Use of solid wastes of the soda ash plant as an adsorbent for the removal of anionic dyes: Equilibrium and kinetic studies. Chem EngJ. 2008;138(1-3):207-14. doi:10.1016/j.cej.2007.06.035.

39. Hameed B, Daud F. Adsorption studies of basic dye on activated carbon derived from agricultural waste: Hevea brasiliensis seed coat. Chem EngJ. 2008;139(1):48-55. doi:10.1016/j.cej.2007.07.089.

40. Witek-Krowiak A. Analysis of influence of process conditions on kinetics of malachite green biosorption onto beech sawdust. Chem Eng J. 2011;171(3):976-85. doi: 10.1016/j.cej.2011.04.048.

41. Najafpoor A, Alidadi H, Esmaeili H, Hadilou T, Dolatabadi M, Hosseinzadeh A, et al. Optimization of anionic dye adsorption ontoMelia azedarachsawdust in aqueous solutions: effect of calcium cations. Asia Pac J Chem Eng. 2016;11(2):258-70. doi:10.1002/apj.1962.

42. Gokce Y, Aktas Z. Nitric acid modification of activated carbon produced from waste tea and adsorption of methylene blue and phenol. Appl Surf Sci. 2014;313:352-9. doi: 10.1016/j.apsusc.2014.05.214.

43. Han J, Du Z, Zou W, Li H, Zhang C. In-situ improved phenol adsorption at ions-enrichment interface of porous adsorbent for simultaneous removal of copper ions and phenol. Chem Eng J. 2015;262:571-8. doi: 10.1016/j.cej.2014.10.018.

44. Yaneva ZL, Koumanova BK, Georgieva NV. Linear and nonlinear regression methods for equilibrium modelling of p-nitrophenol biosorption by Rhizopus oryzae: Comparison of error analysis criteria. J Chem. 2013;2013:1-10. doi: 10.1155/2013/517631.

45. Hamdaoui O, Naffrechoux E. Modeling of adsorption isotherms of phenol and chlorophenols onto granular activated carbon. Part II. Models with more than two parameters. J Hazard Mater. 2007;147(12):401-11. doi: 10.1016/j.jhazmat.2007.01.023. [PubMed: 17289259].

46. Lin SH, Juang RS. Adsorption of phenol and its derivatives from water using synthetic resins and low-cost natural adsorbents: a review.JEnviron Manage. 2009;90(3):1336-49. doi:10.1016/j.jenvman.2008.09.003. [PubMed: 18995949]. 